\title{
TERTÚLIA LITERÁRIA DIALÓGICA E A EDUCAÇ̃̃o DE JOVENS E ADULTOS: POTENCIALIDADES DA LEITURA DE CLÁSSICOS COMO EXPERIÊNCIA DE FORMAÇÃO PARA E COM PESSOAS POUCO ESCOLARIZADAS
}

\author{
Tammy Silveira Ito (Mestrado em Educação - UNESP) \\ Prof $^{\mathrm{a}}$. Dr ${ }^{\mathrm{a}}$. Maria Rosa Rodrigues Martins de Camargo (Orientadora)
}

\section{RESUMO}

Este trabalho apresenta uma pesquisa de mestrado em andamento, cujo objetivo é analisar o aspecto formador da leitura a partir da realização da Tertúlia Literária Dialógica (TLD) em sala de aula com alunos da Educação de Jovens e Adultos de uma instituição do município de Rio Claro/SP. A TLD é uma atividade de leitura dialógica e coletiva dos clássicos da literatura, na qual as pessoas não somente interpretam o que o autor quis dizer em determinada obra, mas constroem compreensões do que foi lido a partir do mundo da vida. Dois aspectos são considerados no percurso da pesquisa: a seleção coletiva da obra clássica, buscando compreender o que é um livro clássico para pessoas que ora retomam o processo de escolarização, e os encontros quinzenais para a leitura do livro selecionado. Além dos dados coletados por meio de observação, registro em diário de campo e gravação da participação dos alunos na atividade, também são analisados alguns materiais escritos produzidos pelos participantes sobre possíveis afetações provocadas pela leitura. A pesquisa contribui para a ampliação do contato das pessoas pouco escolarizadas com as obras clássicas bem como a ampliação de perspectivas de leitura.

Palavras-chave: Tertúlia Literária Dialógica - clássicos - leitura

\section{INTRODUÇÃO}

(...) mas talvez não saibamos o que é ler, talvez ler seja outra coisa que o que sabemos, que o que fazemos, que o que queremos...talvez as possibilidades da leitura estão reduzidas por nosso saber ler, nosso poder ler, nosso querer ler...talvez não paramos para pensar...e aqui, parar para pensar, significa simplesmente converter em problema tudo o que já sabemos (LARROSA, 2004, p.314).

Eis que Jorge Larrosa incendeia a pergunta-centelha do trabalho que se segue. Afinal, o que é ler? Ou melhor: o que é ler clássicos com pessoas pouco escolarizadas?

Adianto-lhe, caro/a leitor/a, que ao final desse texto você não terá a resposta para essa questão e também nem é a pretensão dessa escrita. Você se deparará com perguntas que se estendem a várias direções e que estão em vias de composição de uma dissertação de mestrado. Neste texto, que agora o/a convido para um diálogo, compartilho minha pesquisa de mestrado em andamento, cuja proposta é pensar no ato de ler como experiência de formação a partir do desenvolvimento da atividade de Tertúlia Literária Dialógica em sala de aula com alunos/as da Educação de Jovens e Adultos. 


\section{SEMINÁRIO DE PESQUISA EM CIÊNCIAS HUMANAS - SEPECH \\ Humanidades, Estado e desafios didático-científicos \\ Londrina, 27 a 29 de julho de 2016}

Esqueçamos por um momento daquele conceito de formação entendido como trajetória daquilo que virá a ser, ou seja, como um caminho normatizado a ser percorrido e ao final será algo. Essa não é a formação que, com Larrosa $(2004,2010)$, proponho pensar.

A experiência de formação aqui entendida envolve uma dissolução de todos os esquemas interpretados, dados e conhecidos, para que possamos nos lançar à aventura de percorrer o mundo: uma viagem de desaprendizagem. Nesta viagem de abandono das seguranças do mundo administrado e configurado, o mundo passa a se apresentar aberto e disposto a ser lido de maneiras-outras.

Nessa formação, todos os (des) são bem-vindos: (des)informar; (des)contruir; (des)estabilizar; (des)aprender; (des)cobrir; (des)dizer; (des)fazer...De todos os (des) rumo a uma expedição em que estamos expostos e dispostos a ser afetados.

Minha aposta seria pensar a formação sem ter uma ideia "prescrita" de seu desenvolvimento nem um modelo normativo de sua realização. Algo assim como um devir plural e criativo, sem padrão nem projeto, sem uma ideia prescritiva de seu itinerário, e sem uma ideia normativa, autoritária e excludente de seu resultado (...). E creio que uma prática da leitura como acontecimento da pluralidade e da diferença, como aventura rumo ao desconhecido e como produção infinita de sentido poderia contribuir para esse pensamento aberto sobre a formação. (LARROSA, 2010, p.12, grifo nosso).

E essa prática de leitura de acontecimento da pluralidade e de produção infinita de sentido encontra espaço e condição na Tertúlia Literária Dialógica (TLD) ${ }^{1}$. Isso porque a TLD se apresenta como atividade de leitura que tem a ver com a subjetividade do leitor/a; ou seja, não somente o que ele/a sabe (conteúdos), mas, principalmente com o que ele/a é (suas experiências, seu mundo de vida, seu contexto). Nesse sentido, a leitura não está atrelada somente à aquisição de conhecimentos - o que se faz importante, pois lendo sabe-se mais que antes, (in)forma-se mais; no entanto, permanece o/a mesmo/a frente ao que lê, pois não (de)forma e não (trans)forma.

$\mathrm{Na}$ TLD, o objetivo não é deixar se encerrar com o que foi dito pelo autor/a, interpretado pelo/a professor/a e assimilado entre os/as participantes. Nesta atividade, a leitura não se acomoda, mas, de outro modo, incomoda, inquieta, abre, silencia, grita e extrapola.

Mas, leitor/a, se até agora você não está se perguntando, por que, dentre inúmeras "práticas" de leitura, escolhi a Tertúlia Literária Dialógica como um espaçomomento possível para uma leitura como formação, eu lanço a questão aqui e encaminho para o próximo item com as devidas apresentações sobre tal atividade de leitura.

\footnotetext{
${ }^{1}$ Daqui em diante será usado o termo TLD para se referir à atividade da Tertúlia Literária Dialógica.
} 


\section{SEMINÁRIO DE PESQUISA EM CIÊNCIAS HUMANAS - SEPECH \\ Humanidades, Estado e desafios didático-científicos \\ Londrina, 27 a 29 de julho de 2016}

\section{TERTÚLIA LITERÁRIA DIALÓGICA: LEITURA COMPARTILHADA DE CLÁSSICOS DA LITERATURA.}

A TLD é uma atividade cultural e educativa baseada na leitura coletiva e dialógica dos clássicos da literatura universal, na qual "os participantes não apenas interpretam aquilo que o autor ou a autora quis dizer, mas compartilham compreensões e experiências do mundo da vida, descolonizando o conhecimento" (MELLO; BRAGA; GABASSA, 2012, p.132). Nesta atividade, os sentidos e significados extrapolam para além do que está escrito no livro, e se constroem nas diferentes contribuições que os/as participantes compartilham ao dialogar sobre suas compreensões diante do que foi lido.

A TLD nasceu como uma atividade educativa e não-formal na escola de pessoas adultas "La Verneda de San Marti" (Barcelona/ Espanha), no ano de 1978. Tal escola surgiu num contexto de pós-ditadura e como nos conta Flecha e Mello (2005, p.29), "pessoas do bairro invadiram um antigo prédio e ali fundaram a escola que, com educadoras e educadores progressistas, constitui-se num espaço de democracia deliberativa". Foi, portanto, num contexto de transição democrática na qual se lutava por um modelo mais democrático e alternativo de educação de pessoas adultas, que a atividade foi criada e inspirada nas iniciativas educativas libertárias que cresciam rapidamente na Espanha.

De acordo com Girotto (2011), a Tertúlia Literária Dialógica chegou ao Brasil através do Núcleo de Investigação e Ação Social e Educativa (NIASE/ UFSCar), a partir do pós-doutorado de sua coordenadora junto à escola "La Verneda de San Marti", nos anos de 2001 e 2002. O primeiro lugar onde a atividade foi estabelecida foi na Universidade da Terceira Idade (UATI/ São Carlos). A partir de então, o NIASE expandiu a realização de TLD para salas de EJA e centros comunitários. Em 2005 dá-se início às primeiras experiências da atividade com crianças e adolescentes.

A Tertúlia Literária Dialógica se diferencia de outras atividades de leitura, pois segue uma lógica de funcionamento, assim como sintetiza Flecha:

La tertulia literaria se reúne em sesión semanal de dos horas. Se decide conjuntamente el libro y la parte a comentar en cada próxima reunión. Todas las personas leen, reflexionan y conversan com familiares y amistades durante la semana. Cada um trae un fragmento elegido para leerlo en voz alta y explicar por qué le ha resultado especialmente significativo. El diálogo se va construyendo a partir de esas aportaciones. Los debates entre diferentes opiniones se resuelven sólo a través de argumentos. Si todo el grupo logra um acuerdo, se estabelece como la interpretación provisionalmente verdadera. Si no llega a un consenso, cada persona o subgrupo mantiene su propria postura; no hay nadie que dilucida la concepción certa y la incorrecta en función de su posición de poder (FLECHA,1997,p.17-18).

Outra característica fundamental que diferencia a Tertúlia Literária Dialógica de outras atividades de leitura é que se leem somente os clássicos da literatura universal. Calvino (1993, p.16) já sinalizava em sua obra, de forma genial, que "ler os clássicos é melhor do que não ler os clássicos". O autor apresenta quatorze propostas de definição de clássico que nos ajuda a pensar nas razões para ler desse tipo de obra. Na TLD, um dos principais motivos da leitura dos clássicos é que estas obras refletem com grande 


\section{SEMINÁRIO DE PESQUISA EM CIÊNCIAS HUMANAS - SEPECH \\ Humanidades, Estado e desafios didático-científicos \\ Londrina, 27 a 29 de julho de 2016}

qualidade e profundidade temas humanos (fome, tristeza, inveja, pobreza, amor, amizade, raiva, etc.) que são universais, independente da cultura ou da época. Além disso, a escolha dos clássicos para a atividade se dá pela democratização ao acesso a esse tipo de obra, bem como descontruir muros culturais colocados pelos discursos dominantes de que os clássicos são reservados apenas para a "elite" que detém um longo saber acadêmico para ler tais obras "complexas".

Esta atividade de leitura tem como base teórico-metodológica o conceito de Aprendizagem Dialógica, que diz respeito a uma maneira de conceber não só a aprendizagem, mas também as interações. Os princípios que pautam esse conceito são:

- Diálogo igualitário: de acordo com Flecha (1997), o princípio de diálogo igualitário é embasado principalmente em outras duas formulações: a teoria da Ação Comunicativa elaborada por Jürguen Habermas, e o conceito de Dialogicidade de Paulo Freire e "implica tomada de posição no mundo recusando os lugares de privilégio, bem como a valorização das falas com base nos lugares ocupados pelos sujeitos que as pronunciam" (MELLO; BRAGA; GABASSA, 2012, p.48). Assim, o diálogo é igualitário quando se considera as diferentes contribuições em função da validez dos argumentos e não considerar apenas as posições de poder de quem fala.

- Inteligência cultural: tal princípio defende que todos/as têm inteligência e esta está reportada ao seu contexto cultural. Dessa forma, cada sujeito se forma na relação com todas as outras pessoas que interage ao longo de sua vida. A inteligência cultural refere-se, portanto, à capacidade que todos os sujeitos têm de transferência dos conhecimentos a novos contextos, em determinadas condições.

- Transformação: o princípio de transformação na Aprendizagem Dialógica demonstra modificações profundas nas relações familiares, pessoais e profissionais, que muitas vezes podem estar no âmbito do dia-a-dia e mudanças no nível do "micro", mas que refutam teorias que valorizam apenas a transformação em que se muda o todo. É preciso constatar que a relação entre as pessoas também geram sociedade e educação e, portanto, podem sim, transformá-las.

- Dimensão instrumental: no princípio da dimensão instrumental na Aprendizagem Dialógica rechaçam-se concepções que fazem oposição entre o diálogo e o instrumental. Pelo contrário, a Aprendizagem Dialógica intensifica e aprofunda a aprendizagem instrumental, entendendo que todas as pessoas têm o direito de aprender os conteúdos socialmente estabelecidos.

- Criação de sentido: no princípio de criação de sentido "aposta-se na possibilidade de enfrentar o desafio de recriar o sentido para a nossa existência no contexto atual" (MELLO; BRAGA; GABASSA, 2012, p.68), ou seja, implica que o sujeito se veja como protagonista de sua própria existência e que o diálogo se faça numa relação horizontal. Assim, na TLD o sentido de compartilhar palavras provocadas pela leitura com o restante do grupo ajuda a recriar continuamente o sentido global de suas vidas.

- Solidariedade: se a Aprendizagem Dialógica pressupõe o diálogo de forma horizontal e a superação dos diferentes tipos de segregação e exclusão, a solidariedade é imprescindível nas relações, uma vez que ela "(....) é o elo que mantém os sujeitos conectados num pertencimento ao mesmo mundo social" (MELLO; BRAGA; GABASSA, 2012, p.71). Ou seja, não é possível dialogar se o sujeito se considera o único no mundo, se não se solidarizada com o restante do grupo. É válido lembrar que o 


\section{SEMINÁRIO DE PESQUISA EM CIÊNCIAS HUMANAS - SEPECH \\ Humanidades, Estado e desafios didático-científicos \\ Londrina, 27 a 29 de julho de 2016}

conceito de solidariedade que se aposta aqui é a solidariedade verdadeira defendida por Freire (2005).

- Igualdade de diferenças: o princípio da igualdade de diferenças na Aprendizagem Dialógica afirma que a verdadeira igualdade inclui o mesmo direito de qualquer pessoa viver de forma diferente, sem uma homogeneização cultural ou formatação de um percurso, mas prevalecendo a igualdade na garantia de direitos.

É possível afirmar que só é Tertúlia Literária Dialógica se a atividade é inspirada pelos sete princípios anteriormente citados. Do contrário, o que existem são outras práticas de leitura, que são totalmente válidas e importantes em determinados contextos. No entanto, diante da perspectiva de leitura que se assume nesse trabalho, a TLD e a Aprendizagem Dialógica se apresentam como espaço-momento-possibilidade para o desenvolvimento da leitura como experiência de formação ancorada nos clássicos da literatura.

A Tertúlia Literária Dialógica é uma atividade na qual estou envolvida/comprometida há aproximadamente quatro anos. Meu primeiro contato com essa atividade foi durante a graduação, no ano de 2012, através de um grupo de estudos. No ano seguinte, em 2013, a TLD culminou em um projeto de extensão no qual fui bolsista, onde desenvolvia a atividade com alunos/as do primeiro segmento do ensino fundamental. Já em 2014, após um ano de prática e diversas experiências com essa atividade de leitura, o número de participantes do projeto aumentou, tendo como foco principal, além dos alunos/as do primeiro segmento do ensino fundamental, os/as educandos/as da Educação de Jovens e Adultos. E é nessa experiência com jovens e adultos que fui afetada; é a partir daí, que o sonho segue para a pós-graduação e a pesquisa se volta para e com pessoas pouco escolarizadas.

Compartilho, no item a seguir, o início do desenvolvimento da atividade de Tertúlia Literária Dialógica com jovens e adultos, destacando, principalmente, o momento de seleção da obra clássica a ser lida na atividade, e os primeiros encontros marcados pelo contato com tal objeto cultural e as compreensões que os participantes criam em torno da leitura.

\section{A ARTE DOS ENCONTROS: AFETOS COMPARTILHADOS A PARTIR DA LEITURA DE DOM CASMURRO.}

\section{Da seleção}

A pesquisa em questão está sendo desenvolvida com uma turma que abrange alunos/as (todos maiores de 18 anos) do primeiro segmento ( $1^{\mathrm{a}}$ à $4^{\mathrm{a}}$ série) da modalidade de Educação de Jovens e Adultos de uma escola pública do município de Rio Claro (SP).

Participam da pesquisa nove mulheres e sete homens com idades que variam de 18 a 74 anos, e também a professora da turma. Em relação à leitura e escrita desses educandos, alguns são alfabetizados; outros em vias de; e ainda existem dois dentre o grupo que é a primeira vez que frequentam uma escola.

De uma forma geral, essa é a turma que se apresenta a mim e que aqui, opto por não entrar em detalhes, pois não vou falar pelo o que lhes falta (falta saber ler, falta saber escrever, falta ter ensino fundamental completo, etc.). O que me interessa, neste momento, não diz respeito ao que deveriam ser ou onde deveriam chegar, mas 


\section{SEMINÁRIO DE PESQUISA EM CIÊNCIAS HUMANAS - SEPECH \\ Humanidades, Estado e desafios didático-científicos \\ Londrina, 27 a 29 de julho de 2016}

exatamente como se apresentam: pessoas que estão retomando ou mesmo iniciando o processo de escolarização e se lançaram ao desafio de participar de uma atividade de leitura de clássicos.

A escolha do livro que está sendo lido durante a Tertúlia Literária Dialógica consistiu na primeira etapa do desenvolvimento da atividade na escola e envolveu pontos importantes da Aprendizagem Dialógica, principalmente, porque tal seleção foi feita coletivamente com os/as alunos.

Primeiramente, fiz uma pré-seleção dos livros clássicos existentes na biblioteca da escola. É importante destacar que a biblioteca da escola é o local escolhido para a busca das obras, visto que esse é o espaço primeiro que os/as alunos/as podem procurar os livros. Nesse sentido, a democracia do acesso é pensada no espaço que eles/as têm para continuar a buscar os livros clássicos após o fim da pesquisa.

Do levantamento de livros clássicos realizado na biblioteca escolar, reduzi a quatro obras que levaria aos/as alunos/as para que posteriormente fizessem a escolha: Dom Casmurro (Machado de Assis); A metamorfose (Franz Kafka); O quinze (Raquel de Queiroz); e $A$ hora da Estrela (Clarice Lispector).

O que pautou minha escolha por esses livros? Qual é a ideia de clássico que fomento e que reflete na escolha desses autores? Se por um lado, fiz tal pré-seleção e, portanto, movimentando o sentido em torno do que se configura uma obra clássica, partindo de certos critérios universais e também do que é um clássico nas minhas leituras, por outro lado, foram os/as próprios/as alunos/as que, no processo de escolha da obra a ser lida na atividade, acabaram por definir o que se torna um clássico para eles.

E escolheram...Queriam ler e dialogar sobre Dom Casmurro.

Se os denominados clássicos "continuam a ter muito que dizer a cada geração, porque falam de verdades profundas, inerentes ao ser humano" (MACHADO, 2002, p.82), quais são os grandes "temas humanos" para esses alunos/as? O que a opção pela leitura de Dom Casmurro em detrimento dos outros livros na atividade de TLD pode indiciar sobre o que vem a ser um clássico para pessoas pouco escolarizadas?

Mais do que respostas a essas perguntas, o que se propôs nessa etapa de pesquisa foi a inversão da "lente" da abrangência, muitas vezes não tão consensuais em torno dos critérios definidores em torno de uma obra clássica, para os critérios que determinado grupo de leitores constrói sobre o seu clássico (CALVINO, 1993). Isso significa uma movimentação de sentido produzido pelo livro clássico no leitor/a.

\section{“O que tem nesses livros?": a construção coletiva e dialógica sobre o livro.}

Escolhida a obra, passamos à leitura compartilhada, coletiva e dialógica de Dom Casmurro.

Os encontros são semanais, com duração de aproximadamente uma hora e são divididos em momento de leitura e momento de destaques/ comentários. Após a leitura coletiva de um capítulo ou mais, o diálogo vai se construindo a partir das diferentes interpretações, compreensões e sensações que cada participante se permite e compartilha com o restante do grupo sobre o que foi lido.

O primeiro encontro, em especial, se deu com a apresentação do livro e uma longa conversa sobre as edições da obra. Além dos exemplares existentes na biblioteca da escola, consegui mais dezesseis exemplares emprestados da biblioteca municipal da 


\section{SEMINÁRIO DE PESQUISA EM CIÊNCIAS HUMANAS - SEPECH \\ Humanidades, Estado e desafios didático-científicos \\ Londrina, 27 a 29 de julho de 2016}

cidade. Tais livros são de variadas edições, desde as mais antigas - Editora Ática, 1976 -, até algumas mais recentes - Editora Nobel, 2009.

Diante disso, antes do início efetivo da leitura da obra, fez-se indispensável uma discussão sobre aquele objeto cultural que ali se apresentava: o livro. Enquanto fazia uma rápida apresentação das edições da obra que havia conseguido na biblioteca municipal, a preocupação dos/as participantes pareceria mais séria e profunda:

Participante 5: O que tem de interessante nesse livro, toda história?

Pesquisadora: Toda história? Como assim?

Participante 5: O que tem nesses livros?

Pesquisadora: O que tem dentro dos livros?

Participante 5: É, o que está escrito?

Pesquisadora: A história do Dom Casmurro.

Participante 5: Todos esses?

Pesquisadora: Todos os livros é a história do Dom Casmurro, a mesma história.

Participante 5: Mas a história não tem fim? Porque é muito livro.

Professora: Não, é o mesmo texto.

Participante 6: É uma cópia, é igualzinho, um igualzinho ao outro, o que vai mudar é o número de páginas, o tamanho da letra. ${ }^{2}$

O que é um livro? Ele conta uma história? Mas por que 16 livros? Todos aqueles livros contam a mesma história? Ou um é continuação do outro? Perguntas em que não pensei quando fazia a apresentação das edições, como se aquele objeto cultural fosse algo simples. Antes de qualquer comentário sobre as edições do livro, era preciso, primeiro, conhecer um livro.

Se o livro conta uma história, quem é que conta esta história? Quem é Machado de Assis? Quem é Dom Casmurro? São as mesmas pessoas?

Participante 5: O que é Dom Casmurro?

Participante 2: É o nome do livro, né? Nós vamos descobrir assim que começarmos a ler.

Pesquisadora: Eu acho que logo no comecinho a gente já descobre por que Dom Casmurro. Alguém tem ideia?

Participante 9: Por causa do nome do moço.

Pesquisadora: Do moço?

Participante 9: É, do personagem principal.

Pesquisadora: Ah, do personagem principal. Alguém sabe o que é casmurro?

Participante 10: Mas, é o nome de uma pessoa, né? Ou não?

Pesquisadora: Não entendi a pergunta.

Participante 10: É o nome de uma pessoa? É o nome? Quem criou o livro?

Pesquisadora: Não, quem criou essa história aqui é o Machado de Assis.

Participante 10: Ah tá.

Pesquisadora: Ele que criou a história. Ai ele inventou um personagem para essa história dele, que é o Dom Casmurro. Entendeu? Por exemplo, eu quero escrever um

\footnotetext{
${ }^{2}$ Os encontros são gravados por meio de gravador de áudio e posteriormente transcritos. Todos os diálogos apresentados neste trabalho aconteceram no encontro do dia 30/03.
} 


\section{SEMINÁRIO DE PESQUISA EM CIÊNCIAS HUMANAS - SEPECH \\ Humanidades, Estado e desafios didático-científicos \\ Londrina, 27 a 29 de julho de 2016}

livro, ai eu vou contar uma história e eu vou inventar vários personagens, várias pessoas para minha história, aí eu escolho os nomes. Machado de Assis escolheu Dom Casmurro para ser o personagem principal da história dele. Que nem novela que tem as pessoas lá, né? Aí o autor da novela escolheu o nome dos personagens.

Será que a história que está sendo contada naquele livro foi realmente vivida pelo autor?

Pesquisadora: Se é uma ficção, se é uma história inventada ou se é uma história que ele viveu. O que vocês acham?

Participante 1: Eu acho que ele viveu.

Participante 10: Eu acho também.

Participante 2: Eu acho que ele inventou.

Participante 8: Eu...ele, ele criou.

Participante 9: Eu também acho que ele criou, ele que fez a história.

Professora: Mas viveu essa história?

Participante 9: Não, ele não viveu a história.

Participante 10: Como ele contou a história se ele não viveu?

Participante 9: É...

Pesquisadora: Como ele ia contar a história se ele não viveu? É isso?

Participante 10: Que?

Pesquisadora: Como ele ia contar a história se ele não viveu?

Participante 10: É.

Pesquisadora: Ué, mas a gente inventa história, não inventa?

Participante 9: Que nem na novela, quem vê novela? Lá é história aqui é vida real.

Professora: Mas será que a pessoa viveu naquilo que ele escreveu na história?

Participante 9: Então, da novela, eu acho que não.

Em um único encontro, na qual a leitura da obra ainda nem havia começado e, ainda assim, tais jovens e adultos levantaram pontos importantes a serem pensados sobre o livro enquanto objeto cultural (CHARTIER, 1996) e sobre o ato de ler: O que é um livro? O que é um autor? O que é um personagem? Autor e personagem se confundem em uma história? Qual o limiar entre a ficção e a realidade?

Portanto, ler, naquele momento, era pensar nas questões colocadas acima, ou seja, destrinchar aqueles livros: conhecê-los, indagá-los, provocá-los. E, a partir de então, ler a história de Dom Casmurro...

\section{PARA NÃO CONCLUIR...}

A tempestade que se formou em torno do objeto cultural que se apresentava àqueles jovens e adultos passou, mas, contrariando o ditado popular, a calmaria não veio. Pelo contrário, outra tempestade se formou, agora, na leitura e compreensão da história de Bentinho e Capitu. Leitores/as, não entendam essa tempestade como algo nebuloso, em que o tempo se fecha e estraga o dia. Falo aqui da tempestade pela sua força, sua agitação, e que após ela nada fica como era antes: o chão fica úmido, poças se formam, gotículas de água pousam sobre as plantas, etc. Mesmo que após algumas 


\section{SEMINÁRIO DE PESQUISA EM CIÊNCIAS HUMANAS - SEPECH \\ Humanidades, Estado e desafios didático-científicos \\ Londrina, 27 a 29 de julho de 2016}

horas tudo seque e aparentemente volte ao estado de antes, algo passou, algo aconteceu, algo ficou.

Encontro após encontro, os/as participantes de tal atividade enveredam esforços em entender o que se passa na história, capítulo por capítulo, tentando construir o enredo em suas cabeças. De uma forma geral, o que se tem percebido até o momento é a preocupação que os/as participantes demonstram em decifrar palavra por palavra do que o autor está querendo dizer para então poder compreender a história.

Ora, todos nós queremos entender uma história quando lemos um livro. Qual seria o sentido de ler uma obra se não entendêssemos nada dela? $\mathrm{O}$ que, no entanto, buscamos amenizar nesse movimento de construção de interpretação da história, é não solidificar os sentidos e significados que o livro produz em cada um/a.

E eles/as também percebem que podem compartilhar suas compreensões, entendimentos, sensações, afetamentos sobre o que foi lido. Se, por um lado, num primeiro momento querem construir a cena daquele capítulo, logo em seguida querem dialogar sobre alguma experiência que lembraram a partir do que foi lido.

E tudo perpassa essa conversa: a religião, o amor, o papel do homem e da mulher na sociedade antiga e atual, a força de uma promessa, a infância, a educação, a violência...Temas que se fazem humanos e que acabam por abolir a distância do clássico quando essas pessoas pouco escolarizadas dialogam e convertem aquela história para seu contexto. Não se trata aqui de se reconhecerem em Bentinho, Capitu, José Dias, Dona Glória, Escobar, etc.; mas, a partir dos fios que tecem essa história, pensarem em suas próprias.

Larrosa (1996) afirma que a importância desses personagens está no modo como capturam a nossa imaginação, inspirando concepções inéditas sobre o que é ser humano e, assim, abrindo novas possibilidades de existir:

Las historias ejemplares, y la cultura literaria como su depósito, pueden convertir la historia de nuestras vidas em estereotipo. O pueden enseñarmos a hacer nuestras autocomprensión más rica, más nítida. O nos pueden enseñar la contigencia, la pluralidade histórica y cultural, y la inestabilidad de las formas en que nos construímos a nosostros mismos. O pueden hacer nuesrea autocomprensión más ambigua, más borrosa, más inestable. $\mathrm{O}$ nos pueden sacar de nosotros mismos y transformarnos, convertinos en otros. Em calquier caso, y desde la cultura literaria, nuestra autointerpetación no nos vincula a una esencia de lo que somos, ni a una tradición abstracta, ni a una comunidad humana en general, sino a un nosotros. Al nosotros de los personajes en relación a los cuales hemos aprendido quién somos y qué queremos hacer de nuestra vida (LARROSA, 1996, p.474).

É nesse embate de nos pensarmos em relação a nós mesmos, em relação aos outros e à própria vida, que a leitura passa a ser experiência de formação. Jovens e adultos, que estão retomando o processo de escolarização e, semanalmente, leem, pensam, dialogam, compartilham, argumentam e escolhem expor suas histórias a partir da história de Dom Casmurro. Jovens e adultos, que estão em processo de alfabetização e, semanalmente, se aventuram na Tertúlia Literária Dialógica, fomentando a leitura de clássicos e desestabilizando o que conhecemos por leitura.

Afinal, o que é ler clássicos com pessoas pouco escolarizadas? 


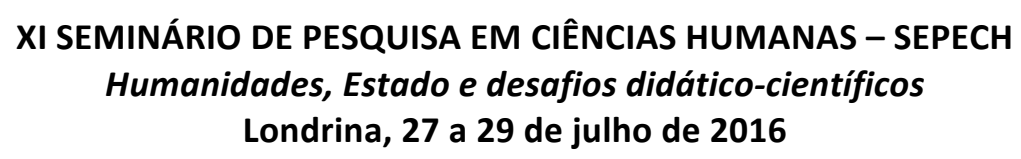

\section{REFERÊNCIAS BILIOGRÁFICAS}

CALVINO, I. Por que ler os clássicos/ Italo Calvino; tradução Nilson Moulin. São Paulo: Companhia das Letras, 1993.

CHARTIER, R. Práticas da leitura/ Roger Chartier (org.); tradução Cristiane Nascimento. São Paulo: Estação Liberdade, 1996.

FLECHA, R. Compartiendo palabras: el aprendizaje de las personas adultas a través del diálogo. Barcelona: Paidós, 1997.

FLECHA, R.; MELLO, R. R. Tertúlia Literária Dialógica: compartilhando histórias. Presente! Revista de Educação - Ano 13 - no 48 - Salvador, mar/2005 (p. 29 - 33).

FREIRE, P. Pedagogia do Oprimido. Rio de Janeiro: Paz e Terra, 2005.

GIROTTO, V. C. Leitura dialógica: primeiras experiências com tertúlia literária dialógica com crianças em sala de aula. Tese de Doutorado. Programa de PósGraduação em Educação, Universidade Federal de São Carlos, São Carlos, 2011.

LARROSA, J. La experiencia de la lectura: estúdios sobre literatura y formación. Barcelona: Laertes, 1996.

LARROSA, J. Linguagem e educação depois de Babel/ Jorge Larrosa; tradução Cythia Faria. Belo Horizonte: Autêntica, 2004.

LARROSA, J. Pedagogia profana: danças, piruetas e mascaradas/ Jorge Larrosa; tradução Alfredo Veiga-Neto. Belo Horizonte: Autêntica, 2010.

MACHADO, A. M. Como e por que ler os clássicos universais desde cedo. Rio de Janeiro: Objetivo, 2002.

MELLO ,R. R; BRAGA, F. M; GABASSA,V. Comunidades de aprendizagem: outra escola é possível. São Carlos: EdUFSCar, 2012. 